\title{
The Effects of Casting and Blending on Properties of Ionomer and the Electromechanical Responses of Ionic Polymer Metal Composite Actuators
}

\author{
Yanjie Wang, Jie Ru, Denglin Zhu, Minzhou Luo, \\ Xiaofeng Liu and Hualing Chen
}

Additional information is available at the end of the chapter

http://dx.doi.org/10.5772/intechopen.72440

\begin{abstract}
As one typical kind of ionic electroactive polymers (iEAPs), ionic polymer metal composites (IPMC) consist of an ionomer and two thin layers of metallic electrode on its both sides. The micro-properties of the ionomer, usually Nafion as the most used ionomer, exert strongly effects on the responses of IPMC actuator. Our works revealed the effects of casting process with different additives (ethylene glycol (EG), dimethyl sulfoxide (DMSO), N, N'-dimethyl formamide (DMF) and N-methyl formamide (NMF)), and blending with sulfonated multi-walled carbon nanotube (sMWCNT) on properties of ionomer and the electromechanical responses of IPMC actuators. Some important properties of casting membrane and sMWCNT/Nafion blending membrane, such as surface morphology, water uptake and ionic exchange capacity, etc., were measured and evaluated. Among the casting membrane-based IPMC actuators, EG based IPMC actuator has larger deformation at $2 \mathrm{~V}$ DC voltage. And a trace amount of sMWCNT can improve the performances of IPMCs significantly for realistic applications.
\end{abstract}

Keywords: ionomer, IPMC actuator, casting, blending, electromechanical responses

\section{Introduction}

As a typical kind of copolymers, an ionomer is an ion containing polymer, which consists of nonionic repeat units and a small amount of ion containing repeat units [1]. In an ionomer, the nonpolar chains are grouped together and the polar ionic groups are attracted to each other. The attractions of ionic units result strongly influence the polymer properties. Due to the presence of non-ionic groups and ionic groups, the membranes made with ionomers are used to 
achieve special ion-exchange ability, such as letting water molecules pass through and not the metal ions. One specific ion-selective membrane is a perfluorosulfonate ionomer which is called Nafion by DuPont, and the chemical formula is shown in Figure 1. The microstructure of Nafion varies in the length of back bones (I) and branches (II) and in the nature of the ionic side group, usually sulfonate anions (III). Usually, Nafion resins can be made into films or tubes and used in the process of production of chlorine, regeneration of spent acids, separations in chemical processing, lithium-sulfur batteries, as well as used in fuel cells and electrodialysis. [2-5]

In past two decades, significant attention has been directed to the field of ionic electroactive polymers (iEAPs), which generates quick and large strain due to the mass transfer effects in itself. [7] As one typical kind of iEAPs, ionic polymer-metal composites (IPMC) are very suitable for actuators and sensors with many unique advantages of large deformation, low actuating voltage, high compliance, lightness, softness, etc [8-10]. A typical IPMC has a sandwich structure (Figure 2(a)), which consists of a matrix membrane, usually Nafion membrane, and two thin metallic electrode layers on both sides of the membrane. So far, Nafion remains as the benchmark for a majority of research and development in IPMC technology [11].

The actuation mechanism of IPMC involves a variety of physical and chemical processes. When an external voltage is applied at the both sides of IPMC, it will induce an electric field gradient across the thickness direction. The ions carrying some solvent molecules will be dragged from one side to another side and results in difference in ion concentrations across the thickness direction. Then the expansion and contraction on both sides of IPMC occur, which consequently results in bending deformation of IPMC (Figure 2(b)) [12].

One of the most important factors seriously affecting the performance of IPMC is the properties of Nafion, which mainly provides the backbone and ion transport medium of IPMC during the actuating process. Commercial Nafion series have a relatively poor thickness range from 50 to $250 \mu \mathrm{m}$, which will finally result in low output force. From the perspective of increasing the output force of IPMC, the easiest and most efficient way is to increase the thickness of the matrix membrane. So far, there are two ways to form thick Nafion: hot pressing [13] and solution casting [14], developed by Lee and Kim, respectively. The former uses hot-press technology to integrate multi-layers of commercial Nafion membranes, which easily result to delamination after actuating IPMC repeatedly [15]. The latter overcome this defect, which can obtain the ionomer with arbitrary shape and thickness. However, the work from [14] did not report more information about the micro-properties of casting ionomer. Other researchers [16-18] researched the formation of casting ionomer a lot for fuel cell and chlor-alkali application. They revealed that temperature, curving time, and the choice of additive affected

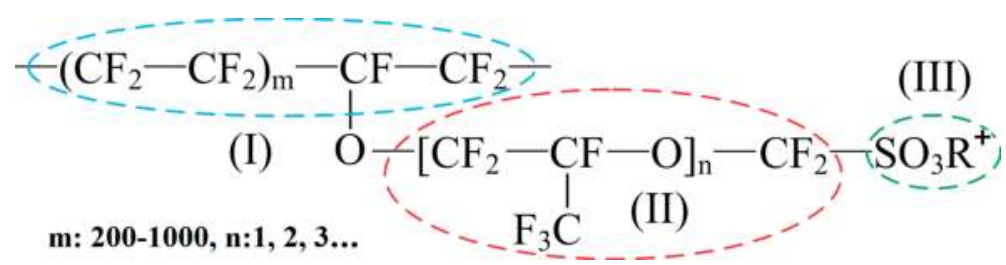

Figure 1. A typical chemical formula of Nafion series [6]. 
(a) Initial state

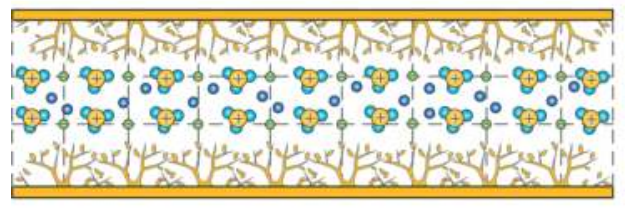

$\phi$ Fixed anions $\circ$ Water $=$ Surface electrode (b) After applying voltage $\circ-$

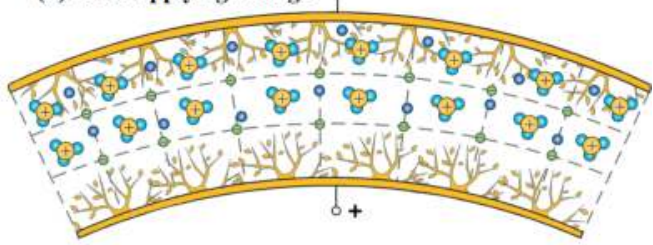

Hydrated cations

Interface electrode

Figure 2. Schematic diagram of the configuration (b) and actuation mechanism of IPMC.

microstructure of ionomer $[19,20]$, in which the effects of curving time and temperature on the micro-properties of casting ionomer have been clearly clarified. From the perspective of the additives, Moore et al. [21] has confirmed that casting ionomer would display worse mechanical intensity and higher solubility without the addition of the high boiling additives. Then researchers [22-25] began to pay attention to the effect of additives and tried to find out that why and how additives seriously affect the morphology formation of casting ionomer. And they experimentally confirmed that the addition of the high boiling additive changed the water content, conductivity and modulus, of casting ionomer. These factors also will exert significant influences on the electromechanical responses of IPMCs based on the casting ionomer.

Another method to improve the performance of IPMC is to blend conductive or nonconductive compounds into Nafion matrix. The emerging nano-scale carbonaceous materials, such as carbon nanotubes (CNTs), graphene, fullerenes, carbon nano-fibers (CNF) and carbon-filled materials and so on, have prompted the research into a new class of actuators consisted of "smart nano-materials"'-carbonaceous materials [26-29]. The mentioned materials just now typically have the advantages of remarkably large specific surface area together with nano-porous structure to guarantee a lot of insertion sites for electrolyte ions [30]. Due to the high strength, stiffness and excellent electrical conductivity of CNTs, CNTs-based composites are widely applied in various research fields [31-33]. CNTs are also applied to improve the performances of Nafionbased IPMCs. Sulfonated multi-walled carbon nanotube (sMWCNT), with sulfonic acid groups $(-\mathrm{SO} 3 \mathrm{H})$ covalently bonding to the surface of MWCNT and very weak Van der Waals' force among the bundles, is water-soluble and possess numerous insertion sites while the mechanical properties are hardly weakened compared to the original MWCNT [34-36]. Therefore, it has been widely used in super capacitors $[37,38]$ and lithium ion batteries $[39,40]$. Considering the working mechanism and characteristics of the Nafion-based IPMCs, sMWCNT is expected to improve the mass transfer performance and elastic modulus, and then result in improvements on the electromechanical and electrochemical performances of the IPMC actuators.

\section{Experimental section}

\subsection{Experimental materials}

The 5 wt. \% Nafion ${ }^{\circledR}$ dispersions (D520) were purchased from DuPont TM. Commercially available Nafion ${ }^{\circledR} 117$ membrane (N117), purchased from DupontTM, was used as a reference. 
Concentrated nitric acid (69.5 wt. \%), sodium hydroxide Sodium p-aminobenzenesulfonate, $\mathrm{NaNO}_{2}, \mathrm{Pd}\left(\mathrm{NH}_{3}\right)_{4} \mathrm{Cl}_{2}, \mathrm{NaBH} 4$, and $\mathrm{N}_{2} \mathrm{H}_{4} \cdot \mathrm{H}_{2} \mathrm{O}$ were purchased from Aldrich. Four additives for casting membranes were purchased from TianLi Chemical Co., including EG, DMSO, DMF and NMF. MWCNT was purchased from the Chinese Academy of Sciences Chengdu Organic Chemical Co. Ltd. All of the materials were analytically pure and used without further purification.

\subsection{Preparation process}

\subsubsection{Solution casting process}

We performed a typical solution casting process of Nafion ionomer as follows: Firstly, we separately pipetted $50 \mathrm{~mL}$ of $5 \mathrm{wt}$ \% Nafion ${ }^{\circledR}$ dispersions into four glass vessels. Subsequently, we in sequence added EG, DMSO, DMF and NMF into four glass vessels with the fixed quantity of $5 \mathrm{~mL}$ respectively. And then treated the solutions by ultrasonic for $0.5 \mathrm{~h}$ for the purpose of uniformity. The solutions were put into oven under vacuum condition with a constant temperature of $80^{\circ} \mathrm{C}$ for $0.5 \mathrm{~h}$. After the volatilization of solvents with low boiling point, the temperature of the oven was turned up to $120^{\circ} \mathrm{C}$ for further curing process. The curing time was set up for $6 \mathrm{~h}$. After the oven cooled down, the glass vessels were took out and then immersed into cool water. The casting ionomer peeled off naturally $5 \mathrm{~min}$ later. To get the acid form of the ionomers, they were immersed in boiling $5 \% \mathrm{H}_{2} \mathrm{O}_{2^{\prime}} 0.5 \mathrm{M} \mathrm{H}_{2} \mathrm{SO}_{4}$ solution and DI water for $1 \mathrm{~h}$, respectively, and finally saved in DI water. As shown in Figure 3, the casting process mainly consists of four steps.

For the convenience, we mark the casting membranes with the additive of EG, DMSO, DMF and NMF as EG, DMSO, DMF and NMF, respectively. During the casting procedure, we only control additive as a variable. Other parameters, such as the precursors, mixed ratio and heat treatment, were employed from the literature [41], as illustrated in Table 1.

\subsection{2. sMWCNT/Nafion blending membrane}

A certain amount of sMWCNT was added to $3 \mathrm{~mL}$ ethylene glycol (EG) and sonicated for $30 \mathrm{~min}$, then the suspensions was mixed with the Nafion solution and stirred for $1 \mathrm{hr}$. in a poly(dimethylsiloxane) (PDMS, Sylgad184) container $(40 \times 60 \times 40 \mathrm{~mm})$. The mixture was evaporated at 90 and $100^{\circ} \mathrm{C}$ for $12 \mathrm{~h}$ successively to cast sMWCNT/Nafion hybrid membrane.

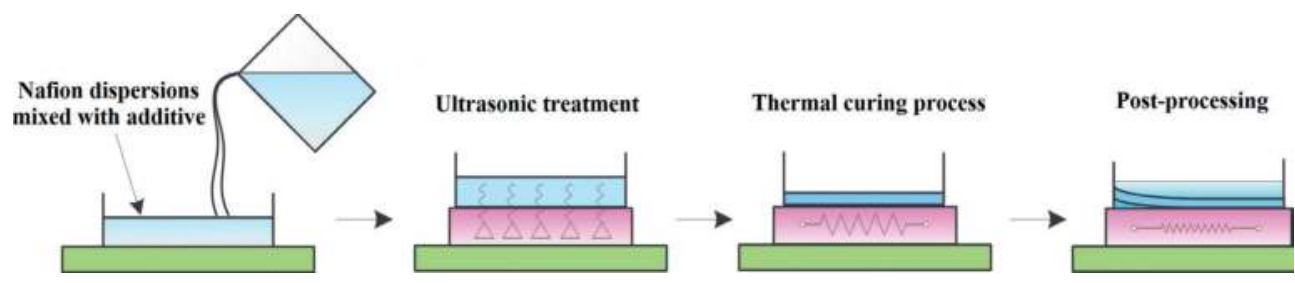

Figure 3. Solution casting procedure. 


\begin{tabular}{lllll}
\hline Samples & Nafion ${ }^{\circledR}$ precursor & Additives & Mixed ratio & Heat treatment $\left({ }^{\circ} \mathbf{C}, \mathbf{h}\right)$ \\
\hline EG & D 520 & EG & $10: 1$ & 120,6 \\
DMSO & D 520 & DMSO & $10: 1$ & 120,6 \\
DMF & D 520 & DMF & $10: 1$ & 120,6 \\
NMF & D 520 & NMF & $10: 1$ & 120,6 \\
Nafion $117^{\text {a }}$ & - & - & - & - \\
\hline
\end{tabular}

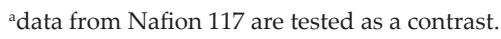

Table 1. Parameters set-up during casting process.

After that, the membrane was annealed at $120^{\circ} \mathrm{C}$ for $1 \mathrm{~h}$. The hybrid membranes were obtained with sMWCNT weight fraction of $0,0.25$ and $0.5 \mathrm{wt} \%$, respectively. Another hybrid membrane with MWCNT content of $0.5 \mathrm{wt} \%$ was also prepared for comparison. The sizes of Nafion membranes are $60 \times 40 \mathrm{~mm} \times(210 \pm 10) \mu \mathrm{m}$ (length $\times$ width $\times$ thickness $)$ under dry state. The composition of the casting solutions and membranes are summarized in Table 2.

\subsection{IPMC fabrication}

The Pd-IPMCs were fabricated via assembling a hybrid Nafion layer and two palladium electrode layers by the impregnation-reduction method, which has been described in detail in our previous report [42]. The major steps were as follows: 1) Surface roughening treatment. The membranes were roughened with a sandblasting machine, then washed with $20 \%$ ethanol solution in an ultrasonic cleaning machine and boiled in $1 \mathrm{M} \mathrm{HCl}$ and water for $30 \mathrm{~min}$, successively. 2) Ion adsorption. This step was to soak the membranes in $\mathrm{Pd}\left(\mathrm{NH}_{3}\right)_{4} \mathrm{Cl}_{2}$ solution to adsorb $\left[\mathrm{Pd}\left(\mathrm{NH}_{3}\right)_{4}\right]^{2+}$ via an ion-exchange process. 3) Reduction. In this step, the adsorbed $\left[\mathrm{Pd}\left(\mathrm{NH}_{3}\right)_{4}\right]^{2+}$ was reduced to metallic state by strong reducing agent $\mathrm{NaBH}_{4}$ to form infiltrate electrode. 4) Further plating. In order to increase the thickness of the surface electrode and reduce the surface resistivity effectively, $\mathrm{Pd}\left(\mathrm{NH}_{3}\right)_{4} \mathrm{Cl}_{2}$ and $\mathrm{H}_{2} \mathrm{NNH}_{2}$ were put into the same solution simultaneously to grow Pd nano-particles above the infiltrate Pd electrode layer. 5) Ion exchange. This step was to exchange $\mathrm{H}^{+}$into $\mathrm{Li}^{+}$(the working ions) by soaking the IPMC strips in $2 \mathrm{M} \mathrm{LiCl}$ solution at room temperature for $24 \mathrm{~h}$. The size of IPMC specimens for final characterization was $30 \times 5 \mathrm{~mm} \times(220 \pm 10) \mu \mathrm{m}$ (length $\times$ width $\times$ thickness) under hydrated condition.

\begin{tabular}{llllll}
\hline Membrane type & \multicolumn{2}{l}{ Casting solution composition } & \multicolumn{2}{l}{ Membrane composition } \\
\hline & CNT (mg) & Nafion (aq) (g) & EG (g) & CNT (mg) & Nafion (s) (g) \\
Pure Nafion & 0 & 19.00 & 4.5 & 0 & 0.9500 \\
$0.25 \mathrm{wt} \%$ sMWCNT & 2.375 & 18.95 & 4.5 & 2.4 & 0.9475 \\
$0.5 \mathrm{wt} \%$ sMWCNT & 4.750 & 18.90 & 4.5 & 4.8 & 0.9450 \\
$0.5 \mathrm{wt} \%$ MWCNT & 4.750 & 18.90 & 4.5 & 4.8 & 0.9450 \\
\hline
\end{tabular}

Table 2. Composition of the casting solutions and membranes. 


\subsection{Characterizations}

\subsubsection{Characterization of ionomer morphology}

We examined the microstructure properties of the casting ionomers using AFM equipment from BRUER, USA with resonance frequency of $380 \mathrm{kHz}$ and selection of tapping mode, which was performed at room temperature and humidity. Due to the fact that surface nanomorphology of the casting ionomers was affected easily by the change of room humidity, we mounted the samples on a silicon substrate. The surface and cross-section morphology of so based IPMCs were observed by SEM (VG3210677 and Hitachi SU-8010). Scanning electron microscopy (SEM) was performed at an accelerating voltage of $20.0 \mathrm{kV}$. All sample cross-sections were obtained by low-temperature cracking, being placed in liquid nitrogen for $5 \mathrm{~min}$ and then broken into pieces.

\subsubsection{Characterizations of the membranes}

\subsubsection{Differential scanning calorimetry (DSC) and thermogravimetric (TG) measurements}

We employed a Thermal Analysis Model DSC1 from Mettler Toledo, Switzerland to perform DSC analysis of the ionomers and so based IPMCs. The weights of test samples were at the range of 4-8 mg. Before DSC observations, the surface of each sample needed to be treated in an oven with the temperature of $80^{\circ} \mathrm{C}$ for $2 \mathrm{~h}$. The heating rate $10^{\circ} \mathrm{C} / \mathrm{min}$ and $\mathrm{N}_{2}$ flow rate $80 \mathrm{ml} / \mathrm{min}$ of DSC was selected. Thermogravimetric (TG) measurements of sMWCNT and MWCNT were carried out by using a TG analyzer (STA 449C, NETZSCH, Germany) at a heating rate of $20^{\circ} \mathrm{C} \mathrm{min}{ }^{-1}$ from 20 to $800^{\circ} \mathrm{C}$ and nitrogen flow rate of $30 \mathrm{~mL} \mathrm{~min}$.

\subsubsection{Water-uptake ratio (WUR)}

In order to measure the WUR, the membranes with different sMWCNT weight fraction were soaked in DI water for $24 \mathrm{~h}$ to be fully saturated; then the membranes were weighed immediately after wiping the water on the surface with filter paper, and the mass was recorded as $M_{\text {wet }}(\mathrm{g})$. After that, the hydrated membranes were dried at $100^{\circ} \mathrm{C}$ for at least $24 \mathrm{~h}$ until a constant mass was obtained, which was recorded as $M_{d r y}(\mathrm{~g})$. The WUR (w) of each membrane can be calculated according to Eq. (1).

$$
w(\%)=\frac{M_{w e t}-M_{d r y}}{M_{d r y}} \times 100
$$

\subsubsection{Ionic exchange capacity (IEC)}

The IEC was measured using the acid-base titration method with $\mathrm{KOH}$ (aq) and $\mathrm{HCl}(\mathrm{aq})$ described in detail in ref. [36] and calculated according to Eq. (2).

$$
I E C=\frac{V_{K O H} \times N_{K O H}}{m_{\text {membrane }}}(m e q / g)
$$

where $\mathrm{V}_{\mathrm{KOH}}$ is the quantity $(\mathrm{ml})$ of $\mathrm{KOH}(\mathrm{aq}), \mathrm{N}_{\mathrm{KOH}}$ is the normality (mol) of $\mathrm{KOH}(\mathrm{aq})$ and membrane is the mass of the membrane. A minimum of three sets of experiments were performed until the percentage error was well within the experimental limits. 

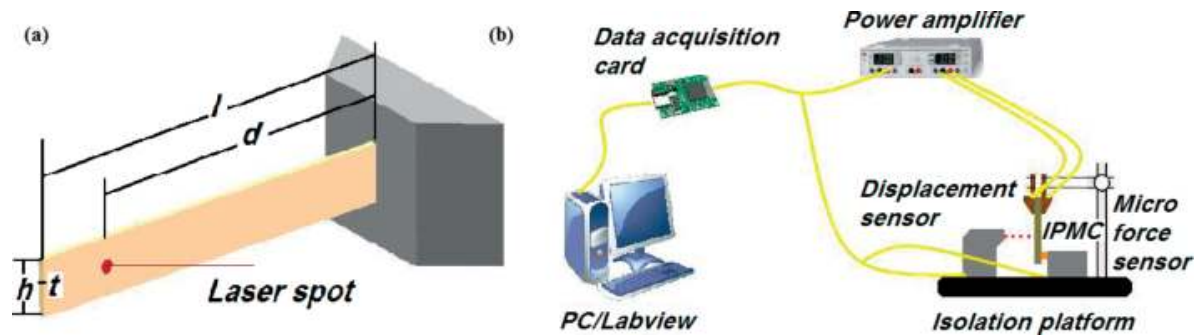

Figure 4. Schematic illustration for dimensions of IPMC strip (a) and experimental apparatus(b).

\subsubsection{Electromechanical test of IPMCs}

The equivalent elastic modulus of IPMCs was measured using the free oscillation attenuation method, and the geometry of the IPMC specimens for the stiffness and electromechanical tests in this work is illustrated in Figure 4(a). During the test, the specimens were prescribed a small initial deformation firstly, and then the natural frequency $f$ of the specimens was obtained by a fast Fourier transform of the free vibration response curve. Every specimen was tested in wet state in two minutes. The equivalent elastic modulus can be calculated via Eq. (4), which is derived from Euler-Bernoulli beam theory.

$$
\mathrm{E}=\left(\frac{2 \pi}{3.52}\right)^{2} \frac{m f^{2} l^{3}}{I}=3.87 \frac{\pi^{2} m f^{2} l^{3}}{h t^{3}}
$$

Electro-active performance was characterized by measuring the displacement and blocking force of IPMC specimens using the same test apparatus described in detail in ref. [42]. The specimen was clamped by a gold-plated copper clamp on one end firstly, while the other end is freestanding with a free length of $30 \mathrm{~mm}$. Then the specimen was applied a constant potential by a Labview software and an arbitrary power supply (HM8143). The displacement and blocking force were measured with a laser displacement sensor (Keyence LK-G80) and a micro force transducer (Transducer Techniques, GSO-10) at the measuring distance of $15 \mathrm{~mm}$, respectively. All the measurements were carried out in air. The current, potential, displacement and blocking force were recorded by the Lab view software simultaneously for $300 \mathrm{~s}$. The experimental apparatus is shown in Figure 4(b).

\section{Results and discussions}

\subsection{Morphology analysis}

As shown in Figure 5, we obtain AFM topography micrographs of polymer chain conformations of the sample EG (a), DMSO (b), DMF (c), NMF (d), with Nafion 117 (e) as a reference. In each subfigure of Figure 5, we defined that bright region is high both in topography and in phase, in which high phase represents the backbone consisted of long polymer chains under tapping mode. Likewise, the gray regions in height reveal the ionic or nano-porous domains with a diameter range of 5-50 $\mathrm{nm}$. We can see some significantly differences by 


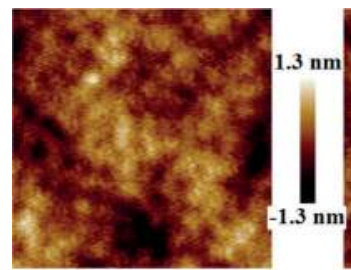

(a) EG

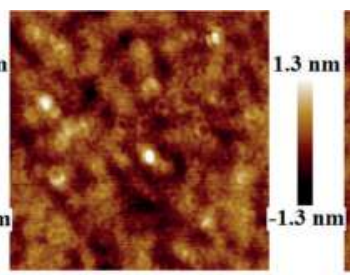

(b) DMSO

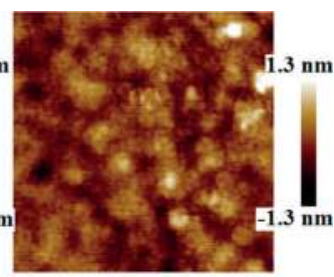

(c) DMF

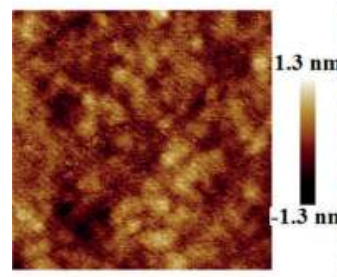

(d) NMF

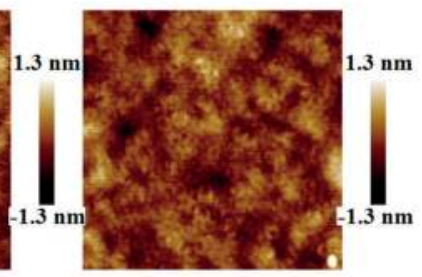

(e) Nafion-117

Figure 5. AFM topography images $(200 \times 200 \mathrm{~nm})$. Images (a), (b), (c), (d), and (e) correspond to the topography of EG, DMSO, DMF, NMF and Nafion 117, respectively.

these subfigures of Figure 5. It is interesting that backbones conformations of casting ionomers are more amorphous and loose in Figures 5(a) and 5(b). On the other side, the polymer chains together with ionic domains are more uniform and compact in Figure 5 (c), (d) and (e), which is responsible for the differences of the compatibilities between Nafion chain molecules and additives. When evaporated from casting solutions, additives assist Nafion side chain sulfonic acid groups to move along with perfluorocarbon backbones so as to form solid membranes. Meanwhile, backbone aggregations in ionomers result in the formation of more sulfonic acid group aggregations, i.e. larger size of ionic clusters, which had been revealed by Ma et al. [22].

Figure 6 shows the inner morphology of P-membrane (a), M-membrane (b, d) and S2-membrane (c, e) at different magnification levels. The two hybrid membranes presented quite rough surfaces, while the P-membrane presented a typically smooth polymer surface with several wrinkles. For the S2-membrane, sMWCNT was homogeneously dispersed in Nafion matrix without any entangled structure or obvious agglomeration, which is advantageous to improve the electrochemical and electromechanical performances of the reinforced membranes and corresponding IPMCs. It is also obvious that the dispersion of sMWCNT was much more uniform than that of MWCNT in Nafion matrix, in that the hydrophilic nature of sMWCNT facilitated their dispersion in the Nafion matrix via the hydrophilic interaction between $-\mathrm{SO}_{3} \mathrm{H}$ groups of Nafion and sMWCNT [43]. The electrode morphology of the S2-IPMC is also shown in Figure 8f. The thickness of the Pt layer on the membrane surface of each IPMC was around 11-16 $\mu \mathrm{m}$, and the range of the surface resistance of each IPMC was around $2-5 \Omega / \square$. As a result, the surface electrodes, without remarkable difference, had no direct correlation with the increasing content of the sMWCNT. Systematic and quantitative correlations of the surface electrode with other fundamental parameters are complex, which is beyond this work and will be discussed in our forthcoming works. 

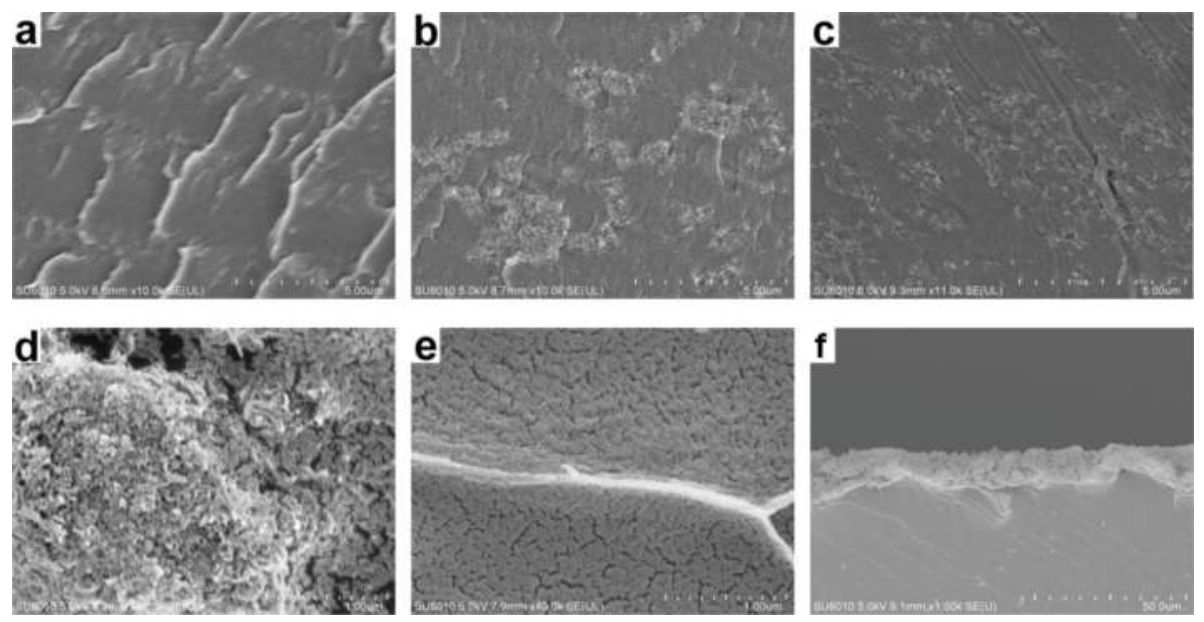

Figure 6. The inner morphology of P-membrane (a), M-membrane (b, d) and S2-membrane (c, e) at different magnification levels, and the electrode morphology of the S2-IPMC (f).

\subsection{DSC and TG analysis of casting and blending Nafion}

In order to evaluate the influence of the additives on thermal behavior of the casting membranes and IPMCs, DSC was performed from 0 to $300^{\circ} \mathrm{C}$. We divided the overall morphology change of the sample into two temperature points based on the temperature range. $110^{\circ} \mathrm{C}$ is the first temperature point (Tg), which appears an intense endothermic valley. We thought the reason was due to the glass transition of the polymeric matrix, and the other temperature point ${ }^{\mathrm{TM}}$ is about $230^{\circ} \mathrm{C}$ [44]. The enthalpy change displayed crystalline region is very little inside the casting ionomers. By testing, we got the Tgs of the samples, which were 104.90, 131.37, 114.81, 109.39 and $117.58^{\circ} \mathrm{C}$ in sequence. Their $\mathrm{Tg}$ values were similar, during which the $\mathrm{Tg}$ of DMSO was highest. The difference of Tgs may be attributed to the morphology change of the polymer chain structure and ion clusters [45]. From the DSC results, the Tms of the samples are almost the same, which only exhibit a small difference. We considered that the curing temperature would result to form the same percentage of crystalline region inside the ionomer. DSC results of casting ionomers are shown in Figure 7 and relative parameters are summarized in Table 3.

From Figure 8a, it can be found that the weight of SCNT nearly decreased by $10 \%$, while the weight of MWCNT only decreased by $5 \%$. In the curve of MWCNT, the small weight loss around $100^{\circ} \mathrm{C}$ was caused by the evaporation of absorbed water molecules, while the weight loss between 220 and $400^{\circ} \mathrm{C}$ was most likely due to the elimination of amorphous carbon [46]. In comparison with MWCNT, the sMWCNT showed a slightly prominent weight loss, which was mainly caused by the decomposition of the grafted azobenzene-4-sulfonic acid and the elimination of amorphous carbon. The slow weight loss between 30 and $130^{\circ} \mathrm{C}$ was also due to the evaporation of absorbed water molecules. The weight decreased dramatically in the range from 220 to $800^{\circ} \mathrm{C}$, which was caused by the decomposition of the side chains of sMWCNT and the elimination of amorphous carbon [40]. The results can also indicate that the sMWCNT would be thermally stable in the membrane casting process. 

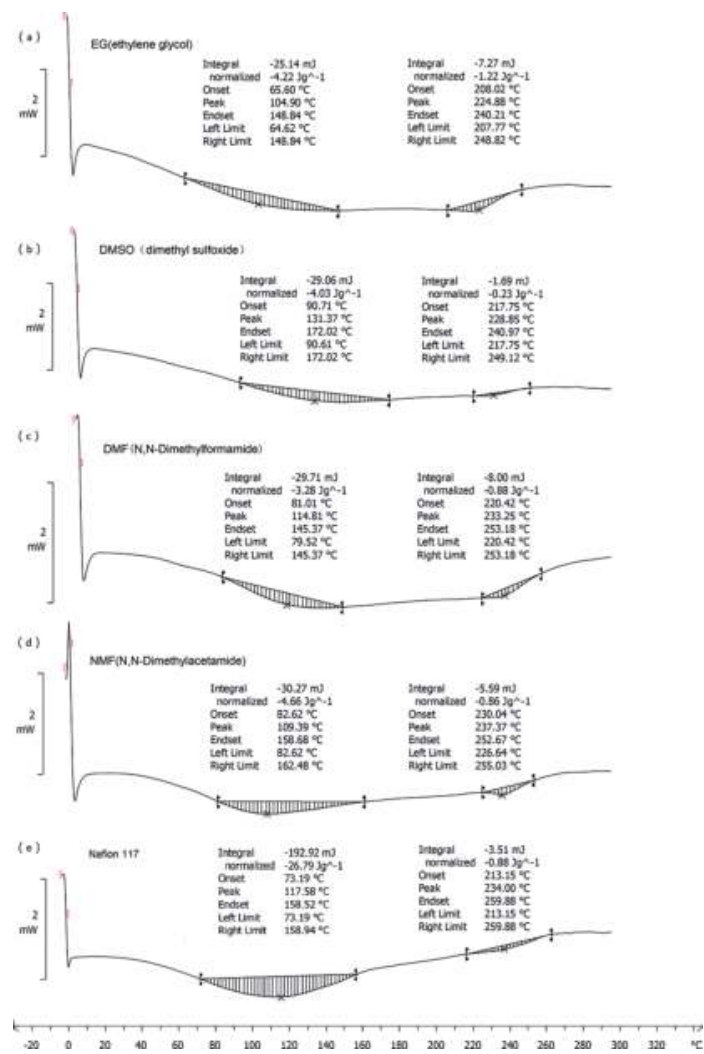

Figure 7. The DSC results of sample EG(a), DMSO(b), DMF(c), NMF(d) and Nafion 117(e).

\begin{tabular}{lllll}
\hline Materials & $\mathrm{Tg} /{ }^{\circ} \mathrm{C}$ & $\Delta \mathrm{H} / \mathrm{mJ}$ & $\mathrm{Tm} /{ }^{\circ} \mathrm{C}$ & $\Delta \mathrm{H} / \mathrm{mJ}$ \\
\hline EG & $104.90 \pm 2.1$ & -25.14 & $224.88 \pm 2.4$ & -7.27 \\
DMSO & $131.37 \pm 1.6$ & -29.06 & $228.85 \pm 3.2$ & -1.69 \\
DMF & $114.81 \pm 2.8$ & -29.71 & $233.25 \pm 4.2$ & -8.00 \\
NMF & $109.39 \pm 2.2$ & -30.27 & $237.37 \pm 3.2$ & -5.59 \\
Nafion 117 & $117.58 \pm 3.1$ & -192.92 & $234.00 \pm 2.6$ & -3.51
\end{tabular}

Table 3. Thermal analysis $(T g, T m)$ of Nafion, modified Nafion and so-based IPMCs.

The TG curves of the S2-membrane and M-membrane shown in Figure 8b, with the same trend, indicate that the hybrid membranes are thermally stable up to ca. $300^{\circ} \mathrm{C}$, which is the same as that of the P-membrane. The similar curves were also obtained by Lage [47] and Almeida [48], respectively. The gradual weight loss in the range between 30 and $300^{\circ} \mathrm{C}$ was mainly due to the evaporation of water molecules. The thermal degradation of the membranes occurred in three stages: the initial stage between 300 and $400^{\circ} \mathrm{C}$ was due to the desulfonation process of $-\mathrm{SO}_{3} \mathrm{H}$ 

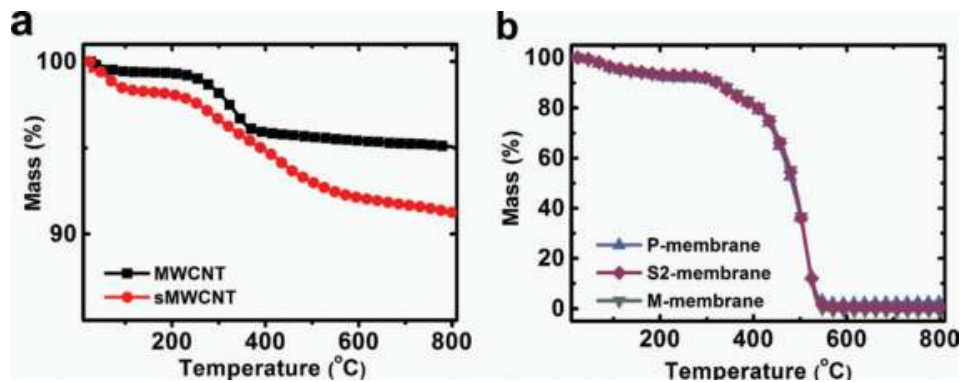

Figure 8. The TG analysis of MWCNT and sMWCNT(a), the P-membrane, S2-membrane and M-membrane(b).

groups, while the second stage between 400 and $480^{\circ} \mathrm{C}$ was caused by the decomposition of the branch chain from the polymer backbone, and the final stage between 480 and $550^{\circ} \mathrm{C}$ was related to the decomposition of PTFE (polytetrafluoroethylene) chain. It can be concluded that the hybrid membranes had the same thermal stability as that of the P-membrane.

\subsection{WUR and IEC of the casting and blending Nafion}

According to vehicle mechanisms and Grotthus 'hopping' theory, water-uptake ratio (WUR) and ionic exchange capacity (IEC) are important factors that strongly affect the hydrated cation migration in Nafion membranes and in terms of mechanical strength and actuation performance of the resulting IPMCs $[49,50]$. The water contents of the casting membranes are summarized in Figure 9. Evidently, EG and DMSO have higher water contents than that of the Nafion 117 in fully hydrated states. The water contents follow the sequence: EG $>$ DMSO $>$ Nafion $117>$ DMF $>$ NMF.

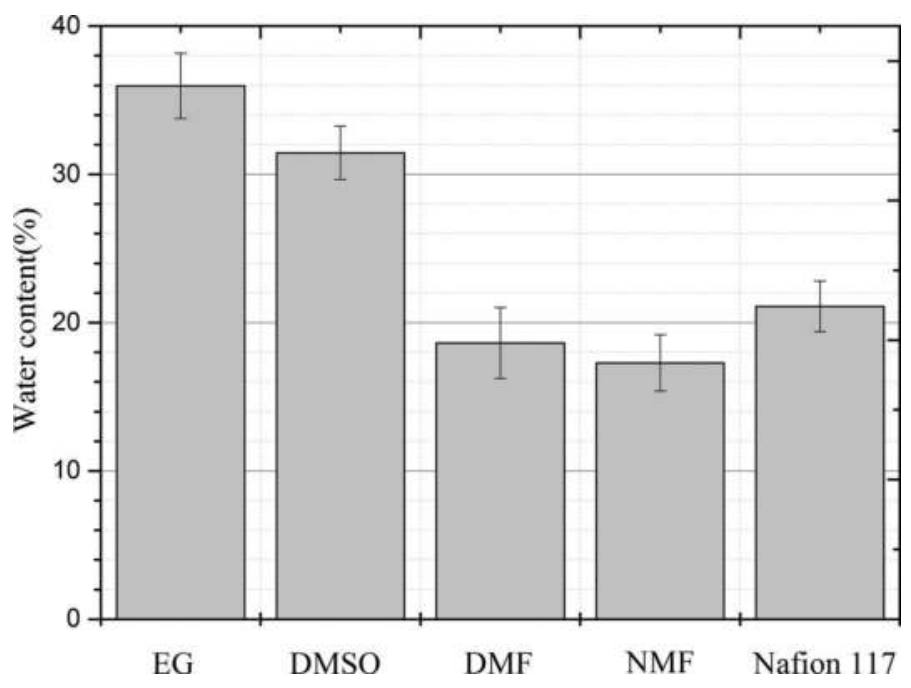

Figure 9. Water content of the samples. 
These results show that the additives exert an important effect on the conformational formation. When the ionomer was absorbed enough water molecules, the conformation of ionic clusters will present different morphologies. The conformation formation of ionomer is very complex due to the interaction between polymer backbone and ionic clusters. When solvents were heated and evaporated out of casting solutions, the side chains of ionomer will curve and shrink to form solid ionomers. During this process, the ionic aggregation occurs as well. Generally, the water content of ionomer is proportional to the size of ionic aggregations [45]. From Figure 8, the results confirmed that the additive exerted its impact on the water content of the casting ionomer, which was similar to the results reported by the reference [22].

The IEC of ionomer decides by the quantity of ionic groups in fixed volume of ionomer, which is consistent to the number of $\mathrm{H}^{+}$in the ionomer. Usually, the increase of the number of sulfonate will result to the increase of IPMCs performance. Figure 4 shows IECs of samples. As shown in Table 4, the used additives lead to the differences of the IECs, of which the IEC of Nafion 117 is highest.

The WUR and IEC of the membranes with different CNT content are summarized in Table 5. The WUR increased as the content of sMWCNT in the polymer matrix increased. The WUR of the S2-membrane was nearly increased by $20 \%$ with comparison to that of the P-membrane. On the contrary, there was a sharp decrease in WUR of the M-membrane (decreased by 15\%), which is consistent with other Nafion-nano-filler systems like MWNT-Nafion [51] and graphene-Nafion [33]. It has been proposed that MWCNT is a hydrophobic particle [51], the substitution of Nafion by MWCNT would lead to a dramatical decrease in water absorption ability of the membrane. Even so, great changes in its hydrophobicity would occur [30] when MWCNT is subjected to chemical modification of MWCNT, like grafting and coating. In this research, the hydrophilic $-\mathrm{SO}_{3} \mathrm{H}$ groups were grafted onto the surface of MWCNT, which provided sMWCNT with the sites of hydrogen bonding with water. Therefore, there was a significant increase in the water absorption capacity of all the sMWCNT/Nafion membranes than that of the M-membrane. It can also be seen that the IEC increased slightly with the content of sMWCNT increasing in the polymer matrix, which is attributed to the great proton exchange ability of $-\mathrm{SO}_{3} \mathrm{H}$ groups. In addition, the increase in WUR and IEC of the sMWCNT/ Nafion membranes maybe due to the sMWCNT increasing the size of the ion clusters and the number of exchange sites for each cluster [52].

\begin{tabular}{ll}
\hline Samples & Ion-exchange capacity (meq/g) \\
\hline EG & $953 \pm 14$ \\
DMSO & $978 \pm 22$ \\
DMF & $996 \pm 10$ \\
NMF & $941 \pm 11$ \\
Nafion 117 & $1104 \pm 16$ \\
\hline
\end{tabular}

Table 4. Ion-exchange capacity of ionomer samples. 


\begin{tabular}{lll}
\hline CNT content & WUR (\%) & IEC(meq/g) \\
\hline $0 \%$ & 22.74 & 0.79 \\
$0.25 \%$ sMWCNT & 23.54 & 0.82 \\
$0.5 \%$ sMWCNT & 27.06 & 0.93 \\
$0.5 \%$ MWCNT & 19.44 & 0.84 \\
\hline
\end{tabular}

Table 5. Properties of the membranes.

\subsection{Electromechanical properties evaluation of IPMCs}

Figure 10 represents the deformations of the EG, DMSO, DMF, NMF, and Nafion 117-based IPMC actuators as a function of time at 2.0 V DC voltages, the tip displacements of which show 4.02, 3.22, 3.17, 1.1 and $6.9 \mathrm{~mm}$, respectively. Nafion-based IPMC exhibits a highest tip displacement. And EG-based IPMC has a larger tip displacement than other samples. This reason is attributed to the higher water content of EG-based IPMC than other samples.

In order to study the dynamic response, the change histories of the deformation of the IPMCs under sinusoidal stimulation under the voltage amplitude of 1 and $2 \mathrm{~V}$ at an excitation frequency of $0.1 \mathrm{~Hz}$ were recorded and shown in Figure 11a and $\mathbf{b}$, respectively. These results indicate that the deformation of the IPMCs can be controlled well using low sinusoidal voltages. Notably, the peak-to-peak (P-P) displacement increased significantly with respect to the increasing content of sMWCNT. For the S2-IPMC, the maximum P-P displacements were

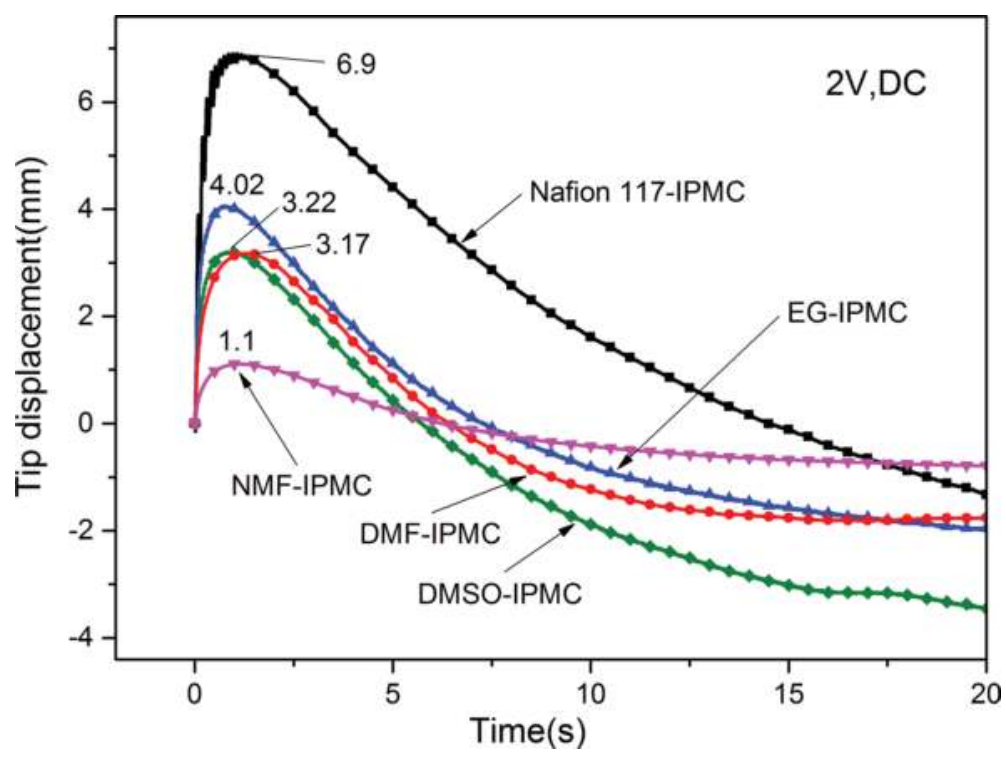

Figure 10. The deformations of the EG, DMSO, DMF, NMF, and Nafion 117-based IPMC actuators. 
a

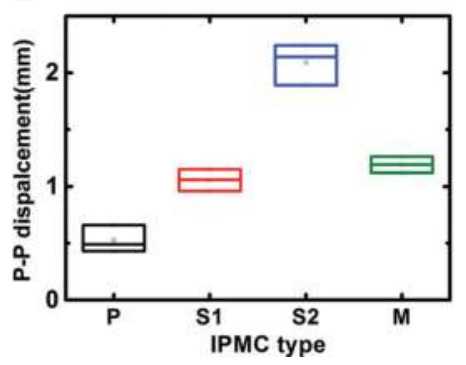

b

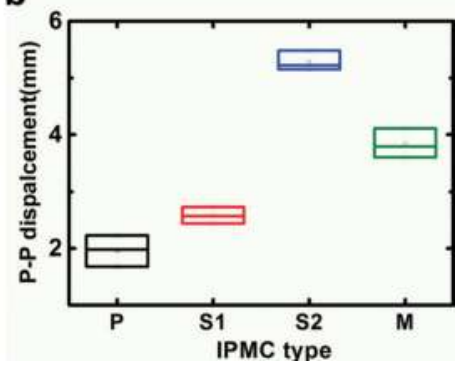

Figure 11. The peak-to-peak (P-P) displacement of harmonic response of the IPMCs under AC $1 \mathrm{~V}$ (a) and AC $2 \mathrm{~V}$ (b) with the excitation frequency of $0.1 \mathrm{~Hz}$ (P: P-IPMC, S1: S1-IPMC, S2: S2-IPMC, M: M-IPMC).

measured to be about 2.06 and $5.28 \mathrm{~mm}$ at the driving voltages of 1 and $2.0 \mathrm{~V}$, respectively. In contrast, the maximum P-P displacements of the P-IPMC were 0.40 and $1.96 \mathrm{~mm}$, and the maximum P-P displacements of the M-IPMC were 1.19 and $3.83 \mathrm{~mm}$ at the same driving voltages, respectively. The DC excitation measurements have also been carried out under DC 1 and $2 \mathrm{~V}$ at $0.02 \mathrm{~Hz}$, respectively. The results, with the same trend to that of the dynamic response, are shown in Figure 12. The maximum displacement of the IPMCs also increased with respect to the content of sMWCNT in the Nafion matrix.

It can be demonstrated that the sMWCNT reinforced IPMCs have much more excellent bending performance than P-IPMC and M-IPMC. Due to the favorable hydrophility, ion-exchange capacity and proton conductivity, sMWCNT showed a higher degree of solvated cation diffusion with comparison to MWCNT. With the incorporation of sMWCNT into Nafion matrix, the improvement in potential difference between the interface electrodes could promote the flux of cations. As a result, the incorporation of sMWCNT induced significant improvement in the deformation of the resulting IPMCs.

Figure 13 shows the maximum peak-to-peak displacement versus the excitation frequency of the harmonic responses under AC 2 V. Obviously, the maximum P-P displacements decreased remarkably as the excitation frequency increased, indicating an inverse relationship between the deformation and the excitation frequency. The decrease in deformation is

a

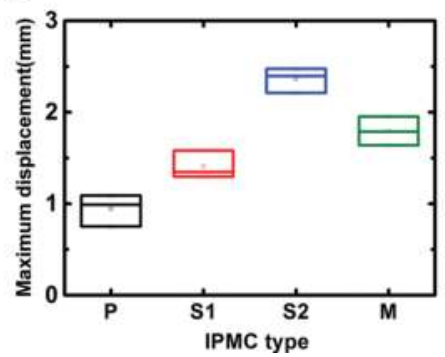

b

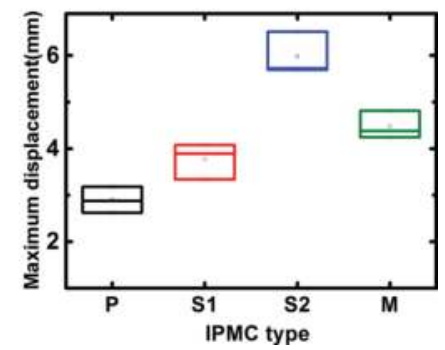

Figure 12. The maximum displacement of step response of the IPMCs under DC $1 \mathrm{~V}$ (a) and DC $2 \mathrm{~V}$ (b) with the excitation frequency of $0.02 \mathrm{~Hz}$. 


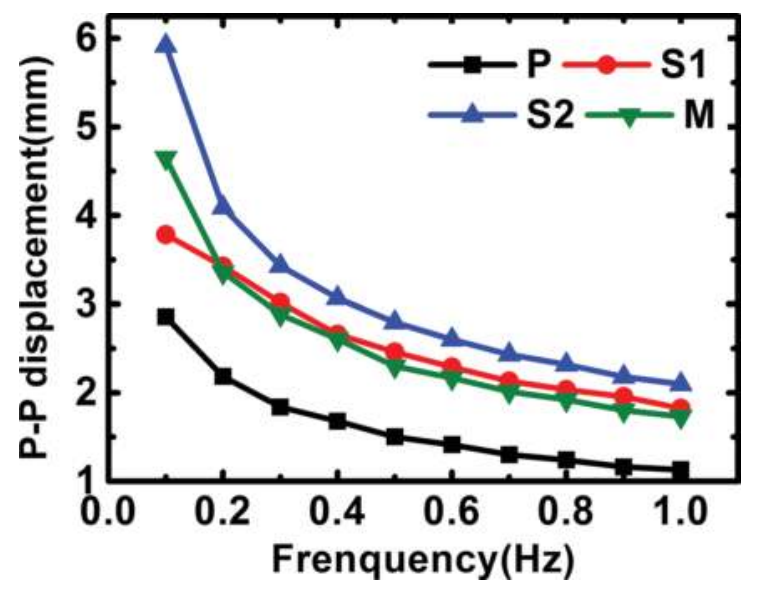

Figure 13. The maximum peak-to-peak displacement versus the excitation frequency of the harmonic responses under AC 2 V.

caused by shortening the driving time of the potential as the frequency increased. Even so, the harmonic response of the S2-IPMC is much better than those of the P-IPMC and M-IPMC, and that of the SWCNT-Nafion IPMCs with the content of $14 \mathrm{wt} \%$ [53]. These results can also demonstrate that a trace amount of the sMWCNT can significantly improve the harmonic response and bending deformation of IPMCs. This may be due to that the reinforcing fillersMWCNT can effectively shorten the hopping distance and reduce the negative impact of water diffusion [54].

\section{Summary and conclusions}

The effects of casting and blending on the performances of ionomers were analyzed, using a series of experimental tests, as well as the so based IPMCs. The ionomers were successfully obtained based on commercial Nafion ${ }^{\circledR}$ dispersion by solution casting process. The sMWCNT/Nafion membranes and crossponding IPMCs were prepared and characterized as well. The morphologies of the membranes were characterized by AFM topography. Among the casting membrane-based IPMC actuators, EG based IPMC actuator has larger deformation at $2 \mathrm{~V}$ DC voltage, whose electromechanical property is most close to that based on Nafion 117. And it is clearly that EG is a more preferable additive during the casting process for the enhancement of IPMC performance. Due to the improvement of water-uptake ratio, proton conductivity and elastic modulus of sMWCNT/Nafion blending membrane, a superior bending deformation and carrying capacity were observed in the sMWCNT/Nafion IPMCs.

Our work has confirmed that additives have great influences on the mechanical properties of the casting membranes and consequently electromechanical coupling of IPMCs. And the sMWCNT/Nafion blending membrane would be promising candidates for use in IPMC actuators. Further research works will focus on exploring more methods to improve the performance of the so based IPMCs for different application background. 


\section{Acknowledgements}

This work is supported by the National Natural Science Foundation of China (NO.51505369 and 51375140), the key development program of Jiangsu Province in China (NO.BE2017071), the Foundation (NO.M20133004) of Changzhou Key Laboratory of Special Robot and Intelligent Technology, the Project of International Cooperation and Exchange of Changzhou (NO. BE2017071) and the Fundamental Research Funds for the Central Universities, P.R. China. The authors gratefully acknowledge the supports.

\section{Author details}

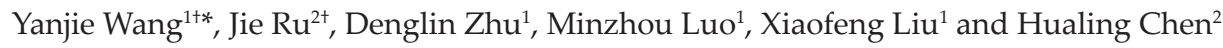

*Address all correspondence to: yj.wang1985@gmail.com

1 Department of Mechanical and Electrical Engineering, Hohai University, Changzhou Campus, Changzhou, People's Republic of China

2 Department of Mechanical Engineering, Xi'an Jiaotong University, Xi'an, People's Republic of China

tThe first two authors contributed equally to this work.

\section{References}

[1] Zhang L, Brostowitz NR, Cavicchi KA, et al. Perspective: Ionomer research and applications. Macromolecular Reaction Engineering. 2014;8(2):81-99

[2] Naterer GF, Suppiah S, Stolberg L, et al. Progress of international program on hydrogen production with the copper-chlorine cycle. International Journal of Hydrogen Energy. 2014;39(6):2431-2445

[3] Bruno JE, Dooley KM. Regeneration of a supported Nafion ${ }^{\circledR}$ catalyst for the doublebond isomerization of octadecenes. Applied Catalysis A: General. 2016;526:70-76

[4] Bauer I, Thieme S, Brückner J, et al. Reduced polysulfide shuttle in lithium-sulfur batteries using Nafion-based separators. Journal of Power Sources. 2014;251:417-422

[5] Lopez-Haro M, Guétaz L, Printemps T, et al. Three-dimensional analysis of Nafion layers in fuel cell electrodes. Nature Communications. 2014;5:5229

[6] Rollet A L, Diat O, Gebel G. A new insight into Nafion structure. The Journal of Physical Chemistry B. 2002;106(12):3033-3036

[7] Tiwari R, Garcia E. The state of understanding of ionic polymer metal composite architecture: A review. Smart Materials and Structures. 2011;20(8):083001 
[8] He Q, Yang X, Wang Z, et al. Advanced electro-active dry adhesive actuated by an artificial muscle constructed from an ionic polymer metal composite reinforced with nitrogen-doped carbon nanocages. Journal of Bionic Engineering. 2017;14(3):567-578

[9] Shen Q, Wang T, Kim K J. A biomimetic underwater vehicle actuated by waves with ionic polymer-metal composite soft sensors. Bioinspiration \& Biomimetics. 2015;10(5):055007

[10] Wang Y, Chen H, Liu J, et al. Aided manufacturing techniques and applications in optics and manipulation for ionic polymer-metal composites as soft sensors and actuators. Journal of Polymer Engineering. 2015;35(7):611-626

[11] Jo C, Pugal D, Oh IK, et al. Recent advances in ionic polymer-metal composite actuators and their modeling and applications. Progress in Polymer Science. 2013;38(7):1037-1066

[12] Wang $\mathrm{Y}$, Zhu Z, Chen H, et al. Effects of preparation steps on the physical parameters and electromechanical properties of IPMC actuators. Smart Materials and Structures. 2014;23(12):125015

[13] Lee SJ, Han MJ, Kim SJ, et al. A new fabrication method for IPMC actuators and application to artificial fingers. Smart Materials and Structures. 2006;15(5):1217

[14] Kim KJ, Shahinpoor M. A novel method of manufacturing three-dimensional ionic polymer-metal composites (IPMCs) biomimetic sensors, actuators and artificial muscles. Polymer. 2002;43(3):797-802

[15] He H, Zhan X, Wang L, et al. The preparation and electromechanical characteristic of the multilayer artificial muscle. Function Materials. 2011;42(B06):529-532

[16] Arimura T, Ostrovskii D, Okada T, et al. The effect of additives on the ionic conductivity performances of perfluoroalkyl sulfonated ionomer membranes. Solid State Ionics 1999;118(1):1-10

[17] Laporta M, Pegoraro M, Zanderighi L. Recast Nafion-117 thin film from water solution. Macromolecular Materials and Engineering. 2000;282(1):22-29

[18] Thomas TJ, Ponnusamy KE, Chang NM, et al. Effects of annealing on mixture-cast membranes of Nafion ${ }^{\circledR}$ and quaternary ammonium bromide salts. Journal of Membrane Science. 2003;213(1):55-66

[19] Li C, Sun G, Ren S, et al. Casting Nafion-sulfonated organosilica nano-composite membranes used in direct methanol fuel cells. Journal of Membrane Science. 2006;272(1):50-57

[20] Mohammadi F, Rabiee A. Solution casting, characterization, and performance evaluation of perfluorosulfonic sodium type membranes for chlor-alkali application. Journal of Applied Polymer Science. 2011;120(6):3469-3476

[21] Moore RB, Martin CR. Procedure for preparing solution-cast perfluorosulfonate ionomer films and membranes. Analytical Chemistry. 1986;58(12):2569-2570

[22] Ma CH, Yu TL, Lin HL, et al. Morphology and properties of Nafion membranes prepared by solution casting. Polymer. 2009;50(7):1764-1777 
[23] Lin HL, Yu TL, Huang CH, et al. Morphology study of Nafion membranes prepared by solutions casting. Journal of Polymer Science Part B: Polymer Physics. 2005;43(21): 3044-3057

[24] Lee SJ, Yu TL, Lin HL, et al. Solution properties of nafion in methanol/water mixture solvent. Polymer. 2004;45(8):2853-2862

[25] Wang Y, Zhu Z, Chen H, et al. Effects of preparation steps on the physical parameters and electromechanical properties of IPMC actuators. Smart Materials and Structures. 2014;23(12):125015

[26] Fennimore AM et al. Rotational actuators based on carbon nanotubes. Nature. 2003;424: 408-410

[27] Guan W et al. Graphitic carbon nitride nanosheet electrode-based high-performance ionic actuator. Nature Communications. 2015;6:7258

[28] Woosung $\mathrm{Y}$ et al. Carbon nanotube-graphene composite for ionic polymer actuators. Smart Materials and Structures. 2012;21:055012 (7pp)

[29] Ru J, Wang Y, et al. Preparation and characterization of water-soluble carbon nanotube reinforced Nafion membranes and so-based ionic polymer metal composite actuators. Smart [29] Materials and Structures. 2016;25(9):095006

[30] Baughman RH et al. Carbon nanotube actuators. Science. 1999;284:1340-1344

[31] Lu L, Chen W. Biocompatible composite actuator: A supramolecular structure consisting of the biopolymer chitosan, carbon nanotube, and an ionic liquid. Advanced Materials. 2010;22:3745-3748

[32] Park IS, Kim SM, Kim KJ. Mechanical and thermal behavior of ionic polymer-metal composites: Effects of electroded metals. Smart Materials and Structures. 2007;16:1090-1097

[33] Thomassin JM et al. Beneficial effect of carbon nanotubes on the performances of Nafion membranes in fuel cell applications. Journal of Membrane Science. 2007;303:252-257

[34] Chang ZY et al. Hierarchically structured carbon-based composites: Design, synthesis and their application in electrochemical capacitors. Nanoscale. 2011;3:529-545

[35] Gupta V, Miura N. Influence of the microstructure on the supercapacitive behavior of polyaniline/single-wall carbon nanotube composites. Journal of Power Sources. 2006;157: 616-620

[36] Ham HT et al. Singlewall carbon nanotubes covered with polypyrrole nanoparticles by the miniemulsion polymerization. Polymer. 2005;46:6308-6315

[37] Hao $\mathrm{Z}$ et al. Tube-covering-tube nanostructured polyaniline/carbon nanotube array composite electrode with high capacitance and superior rate performance as well as good cycling stability. Electrochemical Communication. 2008;10:1056-1059

[38] Bo Get al. Preparation and electrochemical properties of polyaniline doped with benzenesulfonic functionalized multi-walled carbon nanotubes. Electrochimica Acta. 2010;55: 2311-2318 
[39] Seung IL C and Sang B L. Fast Electrochemistry of Conductive Polymer Nanotubes: Synthesis, Mechanism, and Application. Accounts of Chemical Research 2008;41:699-707

[40] Du CY et al. Sulfonation of carbon-nanotube supported platinum catalysts for polymer electrolyte fuel cells. Journal of Power Sources. 2008;176:9-15

[41] Silva RF, De M, Francesco A. Pozio. Electrochimica Acta. 2004;49:3211-3219

[42] Chang LF et al. Manufacturing process and electrode properties of palladium-electroded ionic polymer-metal composite. Smart Materials and Structures. 2012;21:065018

[43] Mahendran Rajagopalan and Il-Kwon Oh. Fullerenol-based electroactive artificial muscles utilizing biocompatible polyetherimide. ACS Nano. 2011;5:2248-2256

[44] R. Linacero, M. L. Rojas-Cervantes, J. De, D. Lopez-Gonzalez. Journal of Materials Science. 2000;35:3279-3287

[45] T. D. Gierke, G. E. Munn, F. C. Wilson. Polymer physics. Journal of Polymer Science. 1981;19: 1687-1704

[46] Chen CM et al. Purification of multi-walled carbon nanotubes by microwave digestion method. Diamond and Related Materials. 2004;13:1182-1186

[47] Lage LG et al. Thermal stability and decomposition of Nafion membranes with different cations using high-resolution thermogravimetry. Journal of Thermal Analysis and Calorimetry. 2004;75:521-530

[48] S H de Almeida et al. Thermal behavior of Nafion membranes. Journal of Thermal Analysis and Calorimetry. 1999;58:569-577

[49] Wang YJ et al. Effect of dehydration on the mechanical and physicochemical properties of gold- and palladiumionomeric polymer-metal composite (IPMC) actuators. Electrochimica Acta. 2014;129:450-458

[50] J Park et al. Electromechanical performance and other characteristics of IPMCs fabricated with various commercially available ion exchange membranes. Smart Materials and Structures. 2014;23:074001 (9pp)

[51] Jung J-H et al. Electro-active graphene-Nafion actuators. Carbon. 2011;49:1279-1289

[52] Bauer F, Pollard MW. Microstructural characterization of Zr-phosphate-Nafion- membranes for direct methanol fuel cell (DMFC) applications. Journal of Membrane Science. 2004:233-239

[53] Landi BJ et al. Single wall carbon nanotube-Nafion composite actuators. Nano Letter. 2002;2(11):1329-1332

[54] Paquette JW, Kim KJ. Ionomeric electroactive polymer artificial muscle for naval applications. IEEE Journal of Oceanic Engineering. 2004;29(3):729-737 
